\title{
MEMBANGUN ACADEMIC SELF-CONCEPT MAHASANTRI PESANTREN NAWESEA
}

\author{
Shulhan Alfinnas \\ STITA Sumenep dan Thariqah Akademik \\ e-mail: shulhan.live@gmail.com
}

\begin{abstract}
Abstrak: Pengkajian ini dimaksudkan untuk membahas konsep diri mahasantri dalam hal akademik di Pesantren Nawesea, Yogyakarta. Sebagai lembaga pendidikan non-formal yang dikelola lembaga swasta, pesantren ini menawarkan program pada pengembangan bahasa asing, pencapaian prestasi akademik dan spiritual untuk mahasantri. Tulisan ini merupakan hasil penelitian lapangan dengan menggunakan metode kualitatif. Teknik pengumpulan data berbentuk observasi mendalam. Penelitian ini menghasilkan beberapa hal penting antara lain: santri wajib mengikuti program pengembangan bahasa Inggris dan bahasa Arab, program motivasi untuk meraih prestasi akademik yang gemilang. Beberapa santri berhasil mendapatkan beasiswa untuk melanjutkan studi di universitas ternama baik di dalam maupun di luar negeri. Alumninya tersebar dalam berbagai lapangan pekerjaan, seperti dosen, peneliti, guru, dan juga karyawan baik negeri maupun swasta. Dengan pelatihan dan pembiasaan ini, konsep diri mahasantri dalam hal akademik terbangun dan dijadikan acuan dalam menentukan masa depan yang cerah.
\end{abstract}

Kata kunci: academic, self-concept, mahasantri, pesantren

Abstract: This study is aimed to discuss mahasantri's self-concept at Nawesea Pesantren, Yogyakarta. As non-formal education managed by private sector, it offers international languages, reaching academic achievement and also spiritual activation for mahasantri. This writing is repots of field research result which used qualitative approach as method. Data collection technique used was indept observation. The result describes the important things that can be a matter to construct our academic-concept namely; every santri must follow program for developing English and Arabic skills, motivation program to achieve distinguished academic. Some santries got scholarships to continue study whether at home or overseas in high reputation universities. The alumni work at various fields like lecturer, researcher, teacher, and also employee in private and public sectors. Through training and habituation, academic self-concept of mahasantri has been being built as highlight to determine a bright future.

Keywords: academic, self-concept, mahasantri, pesantren

\section{A. PENDAHULUAN}

Mahasantri adalah mahasiswa yang memilih tinggal di pondok pesantren dan menimba ilmu untuk mengembangkan potensi dirinya selain dari bangku kuliah. Pondok pesantren merupakan jenis lembaga pendidikan non-formal yang diakui banyak memberikan kontribusi positif dalam perkembangan bangsa Indonesia. Pensantren khusus untuk mahasiswa, sering disebut pesma (pesantren mahasiswa), secara umum dalam pengelolaannya diklasifikasi dalam dua kelompok. Pertama, pesantren yang dikelola oleh perguruan tinggi. Pesantren ini menjadi bagian sistem perguruan tinggi yang sifatnya eksklusif untuk mahasiswa internal kampus tersebut. Kedua, pesantren mahasiswa yang dikelola secara mandiri dan tidak berafiliasi dengan perguruan tinggi tertentu. Pesantren ini bersifat inklusif dalam artian bisa menerima mahasiswa dari berbagai perguruan tinggi di sekitarnya. Pesma 
umumnya memiliki program-program khusus yang ditawarkan sebagai branding dan entitas yang menjadi ciri khas tersendiri seperti program menghafal al-Qur'an, program bahasa asing, program wirausaha, program jurnalistik dan sebagainya.

Pesantren Nawesea adalah salah satu pesantren mahasiswa di wilayah Yogyakarta yang didirikan dan dibina oleh Prof. K.H. Yudian Wahyudi. Pendidikan di pesantren ini dikonsentrasikan pada pengembangan bahasa asing, utamanya bahasa Inggris dan bahasa Arab. Pesantren ini diorientasikan pada peningkatan kapasitas umat Islam dalam hal akademik. Para santri dididik untuk meraih prestasi akademik yang cemerlang dengan lulus cepat dan mendapatkan nilai pujian. Mahasiswa yang menyantri di pondok ini juga dilatih untuk menjadi terampil dalam menggunakan bahasa Inggris dan bahasa Arab serta terampil dalam penulisan ilmiah. Selain itu, para santri dibina untuk meningkatkan aktivitas keagamaan, seperti shalat hajat. Ciri khas pesantren ini adalah program bahasa asing, peningkatan akademik, dan spritualitas. Tiga instrumen ini yang dijadikan program unggulan pesantren untuk membina peserta didiknya agar mampu berdaya saing, baik dalam level regional, nasional, maupun global.

Pendidikan yang berbasis pendekatan culture dan dikelola secara non-formal menerapkan program pendidikan yang berorientasi pada penanaman nilai pada diri peserta didik. Design pendidikan dipraktikkan dalam bentuk program berkelanjutan, meskipun volume dan frekuensinya tidak besar. Pendidikan pesantren dijalankan untuk melatih peserta didik untuk berproses secara alami, mandiri, dan fokus pada orientasi hasil. Proses pembelajaran yang dijalankan di pesantren didasarkan pada kesadaran santri untuk selalu berproses agar mencapai titik tuju (goal orientation). Dorongan yang efektif berupa mengantarkan peserta didik pada realitas dan membimbingnya untuk melakukan langkah yang tepat untuk menyiapkan dirinya dalam menghadapi realitas tersebut. Proses ini dengan sendiri membentuk konsep diri (self-concept) yang menjadi haluan bagi santri untuk menentukan langkah-langkah untuk mencapai tujuan.

"Self-concept is a general view about oneself across various sets of specific domains and perceptions based on self-knowledge and evaluation of values formed through experiences in relation to one's environment" [1] Spinath dan Steinmary mendefinisikan konsep diri tingkat kemampuan seseorang sebagai representasi dari kemampuan kognitifnya [2]. Titik tekan dari definisi ini ialah kemampuan seseorang untuk mendemonstrasikan kemampuannya dari hasil kerja kognisi/berpikir. Konsep diri secara umum dalam hierarkinya diklasifikasi ke dalam beberapa tingkatan yaitu akademik, sosial emosional dan psikis [3]. Academic self-concept adalah representasi kognitif seseorang yang berhubungan dengan performa akademik [4]. Self-concept dalam akademik adalah pola pikir yang dijadikan prinsip bagi seseorang untuk mencapai prestasi akademik dan mendemonstrasikan dalam kehidupan nyata.

\section{B. METODE PELAKSANAAN}

Tulisan ini adalah hasil penelitian ilmiah dengan pendekatan metode kualitatif. Instrument pengumpulan data yang digunakan adalah observasi mendalam. Peneliti meneliti langsung ke lapangan dan terlibat dengan santri untuk menggali data lapangan yang diperlukan. Lokasi penelitian adalah Pondok pesantren Nawesea yang berlokasi di Sekarsuli, Yogyakarta. Penelitian ini dimaksudkan untuk mengkaji bagaimana mahasantri membangun konsep diri dalam hal 
akademik dan bagaimana orientasi keberhasilan akademiknya.

\section{HASIL DAN PEMBAHASAN}

\section{Pengembangan Bahasa Asing}

Bahasa Inggris dan bahasa Arab adalah program yang diwajibkan bagi setiap santri mahasiswa. Setiap hari mahasiswa diwajibkan mengikuti program peningkatan kemampuan bahasa Arab dan bahasa Inggris yang dibina langsung oleh pendiri pesantren atau oleh mentor yang ditunjuk oleh pengasuh. Setelah sholat maghrib, pembelajaran bahasa Inggris dilaksanakan dalam bentuk hafalan struktur, kosa kata, dan juga memahami tulisan-tulisan berbahasa Inggris. Setelah melaksanakan sholat shubuh berjamaah, pembelajaran bahasa Arab dilangsungkan dengan sistem yang sama seperti yang diberlakukan pada materi bahasa Inggris. Selain itu, untuk memberikan pengalaman langsung praktik berbicara, santri melakukan visitasi ke wilayah-wilayah yang terdapat dapat turis asing. Dalam waktu tertentu, Pembina bahasa Inggris mendatangkan tamu asing ke pondok pesantren untuk berdiskusi tentang topik tertentu seperti hubungan international dan budaya. Tamu yang didatangkan biasanya orang yang berlatar pendidikan, seperti peneliti dan dosen.

Bahasa Inggris sebagai salah satu bahasa internasional yang diakui secara resmi oleh PBB adalah mutlak wajib dikuasai oleh masyarakat akademik pada khususnya. Mahasiswa wajib menguasai bahasa Inggris dengan aktif, baik tulisan maupun lisan. Boediono mengatakan bahwa masyarakat akademik (mahasiswa) dituntut untuk mampu hidup dalam masyarakat global. Setiap manusia harus punya pemahaman yang baik terhadap isu-isu yang berkembang dalam skala internasional dan saling menghargai perbedaan budaya [5]. Syarat utama untuk dapat mengikuti dan memahami isu global yang berkembang adalah dengan kecakapan menggunakan bahasa Inggris, karena perkembangan informasi disajikan dalam bahasa tersebut. Untuk bisa menjaga kerukunan dan saling menghormati orang yang berbeda budaya dan negara, masingmasing kita harus memiliki penguasaan bahasa Inggris yang baik untuk membangun komunikasi yang komunikatif dan harmonis. Tanpa kemampuan bahasa ini dengan baik, setiap orang kesulitan dalam interaksi dan membangun hubungan internasional.

Dengan kemampuan bahasa Inggris, setiap orang dengan mudah dapat berkeliling dunia dan dapat mengembangkan kemampuan dirinya. Bahasa ini digunakan sebagai bahasa komunikasi international, bahkan dalam dunia pendidikan bahasa ini sering dijadikan syarat masuk dan atau syarat lulus. Banyak orang hanya bermodal kemampuan bahasa Inggris dan keahlian menulis dapat melanjutkan studi ke luar negeri dengan beasiswa yang bergengsi. Tidak sedikit orang tidak dapat meraih kesempatan emas, meskipun dirinya memiliki banyak prestasi baik akademik maupun non-akademik, tetapi lemah dalam penguasaan bahasa asing. Kemampuan bahasa Inggris dan prestasi akademik yang baik adalah modal utama bagi siapa pun yang hendak melanjutkan pendidikan terutama pendidikan berbeasiswa. Pengelolaan pendidikan di lembaga ini difokuskan untuk membentuk kesadaran pentingnya meraih kedua hal tersebut.

Pengembangan bahasa Arab tidak selancar bahasa Inggris. Beberapa faktor menyebabkan ini terjadi. Pengasuh belum memiliki kader yang bisa dijadikan mentor untuk membina bahasa Arab, sedangkan dirinya harus membagi waktu dengan tugas negara sebagai dosen. Bahasa Arab adalah bahasa yang paling kompleks dan paling 
sulit seperti yang diceritakan oleh pendiri Pesantren Nawesea. Hal ini didasarkan pengalamannya mempelajari bahasa asing. Sejauh ini mahasantri pondok ini cenderung lebih menguasai bahasa Inggris saja atau ada beberapa orang yang bisa bahasa Arab meskipun belum sampai di level advance. Kemahiran santri dalam bahasa Inggris salah satunya dapat dibuktikan dengan perolehan toefl yang tinggi dan meraih beasiswa studi ke luar negeri. Akan tetapi, dalam penguasaan bahasa Arab masih belum maksimal, karena belum maksimalnya sistem pembelajaran bukan karena kegagalan program. Kendala tenaga ahli adalah pemicu utamanya.

Chodidjah mengatakan, “....dan guru sebagai unsur terpenting harus menjadi pemikiran bahkan sebelum proses pengembangan kurikulum itu sendiri” [6]. Guru adalah faktor terpenting dalam setiap program pendidikan. Sebaik apa pun desain kurikulum pendidikan yang hendak diterapkan seseorang keberhasilannya tetap bergantung kepada kemampuan dan profesionalitas guru. Pendidik menempati posisi strategis dalam mewujudkan outcome pembelajaran, sehingga hal yang perlu diperhatikan pertama kali adalah jaminan kualitasnya. Keterbatasan infrastruktur dan sarana pembelajaran akan dicari jalan keluarnya, jika gurunya benar-benar berkualitas dan berdedikasi tinggi. Sebaliknya, jika guru yang ada tidak professional dan bahkan tidak mumpuni, dia akan melakukan tugasnya dengan tidak sempurna. Problem yang dihadapi tidak bisa dipecahkan dan target keberhasilan pembelajaran juga tidak tercapai ketika kemampuan guru belum maksimal.

\section{Academic-Achievement Motivation}

Santri senantiasa dimotivasi untuk mendapatkan prestasi yang sangat baik. Pendiri pesantren mendorong setiap peserta didiknya untuk lulus tercepat dengan prestasi yang gemilang. Mahasantri di sini didorong untuk bisa melanjutkan pendidikan ke jenjang selanjutnya di universitas bergengsi di dunia dengan beasiswa. Pendiri pesantren yang bertindak sebagai coach menumbuhkan semangat anak didiknya untuk lulus dengan IPK di atas 3.50 dan memiliki karya ilmiah yang diterbitkan jurnal berepotasi. Dalam kegiatan yang dilakukan sambil bersantai, pengasuh menekan anak didiknya memiliki kemampuan bahasa yang baik dengan mencapai skor toefl sama dengan di atas 500 dan mampu menuangkan pemikiran dalam bentuk tulisan berbahasa Inggris dan dipresentasikan dalam forum international serta diterbitkan dalam jurnal internasional.

Pengayaan kompetensi di luar bangku pendidikan formal dimaksudkan untuk mengembangkan skill dan kemampuan peserta didik. Selain itu, pengayaan tersebut dimaksudkan untuk memotivasi minat mahasiswa dalam menekuni bidang yang digeluti [7]. Program pendidikan yang dirancang dan dilaksanakan di luar pendidikan formal dimaksudkan untuk mengembangkan kemampuan dan bakat pelajar. Pendidikan nonformal pada umumnya pendekatannya bersifat emosional dan atas kesadaran yang tumbuh dari diri pelajar. Sistem yang dibangun tidak mengikatnya yang berakibat pada hal teknik administratif, jika sudah keluar dari lembaga pesantren. Sederhananya, santri yang sedikit malas dan tidak banyak mengikuti aturan dan sistem yang dijalankan di pesantren tidak mendapatkan risiko administratif ketika keluar pesantren. Hal ini berbeda dengan mahasiswa misalnya, jika tidak rajin dan tidak bersungguh-sungguh mengikuti program dan prosedur perkuliahan akan mendapatkan akibat buruk yang akan terus dirahasiakan minimal dalam hal yang berhubungan dengan administrasi, yaitu record akademiknya jelek dan mempersempit kesempatan untuk mengakses 
program-program yang mensyaratkan lulusan terbaik.

Fakta ini menuntut kesadaran tinggi bagi santri untuk memaksimalkan kesempatan selama di pondok untuk mengembangkan kemampuan dirinya. Berproses dengan penuh kesadaran tinggi akan mengantarkan peserta didik pada keberhasilan yang sesungguhnya. Kemampuan yang diperoleh sangat luar biasa karena motivasi internal dalam diri masing-masing yang menentukan konsistensi usahanya. Kondisi ini jika dibiasakan akan membentuk sistem dalam diri seseorang yang melekat, apabila melakukan apa pun, asasnya kesadaran dan penuh semangat untuk mencapai hasil yang maksimal. Akan tetapi, santri yang belum siap dengan realita ini akan memanfaatkan keadaan untuk hal-hal yang negatif. Ada banyak malfunction yang dilakukan santri yang belum memiliki kesadaran, dalam hal ini santri mahasiswa. Contoh sederhananya santri mencari kesibukan di luar lingkungan pesantren pada jam kegiatan pesantren dan kembali ke pesantren hanya untuk istirahat. Kegiatan tersebut terkadang tidak benar-benar bermanfaat bagi masa depannya, tetapi dirasionalisasi seolaholah itu penting dan mutlak dilakukan sebagai pembenaran dari kealpaan dirinya mengikuti kegiatan pesantren.

Pendapat Lim dan Olive di atas adalah teori penguatan coaching yang dilakukan pendiri pesantren untuk memotivasi santrinya meraih prestasi akademik yang gemilang. Santri dirangsang untuk dapat meraih prestasi akademik sebaik mungkin dan melanjutkan studi di perguruan tinggi terbaik di dunia. Dalam kegiatan motivasi, pembina pesantren menceritakan perjalanan dirinya mengelilingi dunia untuk presentasi di forum internasional. Dia menceritakan dengan detail di hadapan santri-santrinya pahit manisnya perjuangan untuk meraih beasiswa visiting professor di low school, Universitas Har- vard. Tanpa malu atau ragu, dia menceritakan perjalanan hidupnya merintis karier dari bawah mulai kehidupan kecilnya, pengalaman selama di pondok, masa-masa studi di Indonesia, masa mengenyam pendidikan di luar negeri. Hal ini menjadi inspirasi bagi santri untuk menumbuhkan semangat yang tinggi untuk melanjutkan pendidikan dan meraih prestasi yang baik. Santri juga dibina untuk memiliki kepekaan terhadap sosial dan keagamaan dengan dilibatkan dalam beberapa kegiatan pembinaan santri SMP seperti membina bahasa Arab, bahasa Inggris, pembelajaran baca kitab dan al-Quran. Dengan cara ini, santri terlatih untuk menjadi pribadi yang peka terhadap kondisi sosial keagamaan.

Höffler dan Bonim (2017), "Nowadays, most researchers refer to four different goals; (1) Performance goals refer to a focus on attaining success and demonstrating ability, (2) Performance avoidance goals are characterized by the aspiration to not demonstrate incompetence, (3) Learning goals refer to the acquirement of new skill or knowledge, (4) work avoidance represents the aim to avoid or minimize effort in achievement-related task" [8]. Tujuan motivasi di atas ini adalah untuk mendorong peserta didik mencapai kesuksesan dengan lulus cepat dan predikat terbaik. Dengan motivasi itu, mereka menghindari untuk melakukan hal-hal yang di luar kemampuan dan minatnya. Jika hendak melakukan sesuatu yang belum diketahui harus mencari dan menggali ilmunya dulu. Peserta didik selalu didorong untuk meraih keterampilan dan ilmu yang baru.

\section{TEMUAN ATAU DISKUSI}

Mahasantri rata-rata lulus kuliah dengan cepat dan mendapat predikat pujian. Mereka kebanyakan melanjutkan studi lanjut, baik di 
dalam maupun di luar negeri. Kebanyakan mereka melanjutkan kuliah dengan beasiswa. Mereka juga banyak yang bekerja di sektor strategis seperti sebagai dosen dan peneliti. "Academic self-concept is the perception and evaluation that a student has or does about his or her academic abilities" [9]. Konsep diri dalam ranah akademik merupakan persepsi dan evaluasi yang dilakukan seseorang terhadap kemampuan akademiknya. Pertama, setiap orang harus mengonstruksi pikirannya bahwa mencapai IPK sama dengan 3.50 adalah salah satu indikator penting perolehan dan kemampuan akademik. IPK bukan indikator tunggal tetapi ia merupakan salah satu yang mencerminkan kesungguhan seseorang dalam menjalankan proses perkuliahan. Untuk mengukur tingkat validasi tersebut, instrumen lain perlu juga diperhatikan seperti kemampuan bahasa asing, kemampuan menulis ilmiah dan kontribusi nyata di tengah masyarakat.

Kedua, orang tersebut harus mampu mengevaluasi perolehan akademiknya dengan cara memperhatikan akseptabilitas dirinya di tengah masyarakat dan lapangan pekerjaan seleksinya ketat atau studi lanjut dengan beasiswa yang kompetitif. "Academic self-concept has been strongly linked to academic achievement" [10]. Konsep diri tentang akademik sangat erat hubungannya dengan pencapaian akademik, karena seseorang meraih hasil akademik yang baik, karena dalam dirinya telah terbangun konsep diri tentang akademik yang baik. Tanpa konsep diri yang baik, mahasiswa sulit bisa mencapai prestasi dalam dunia akademik, karena sebagaimana yang kita ketahui dunia kuliah selain mengikuti perkuliahan di bangku kuliah juga banyak godaan kegiatan-kegiatan kemahasiswaan yang jauh lebih menarik. Apabila konsep dirinya belum sempurna, ada kemungkinan mahasiswa kehilangan orientasi dan fokus, kemudian mela- kukan kegiatan-kegiatan merugikan secara tidak langsung.

\section{E. SIMPULAN DAN SARAN}

Academic self-concept mahasantri dibangun melalui peningkatan bahasa asing dan kegiatan motivasi untuk meraih prestasi. Konsep diri dalam hal akademik sangat menentukan dalam pencapaian prestasi mahasiswa. Untuk dapat menjadikan mahasiswa menggapai prestasi yang gemilang, mahasiswa harus dibangun kesadaran dirinya tentang pentingnya lulus cepat dengan IPK yang tinggi dan dapat berkiprah dalam kehidupan nyata. Prestasi akademik yang baik, kemampuan bahasa asing, dan kepekaan sosial merupakan hal penting yang ditambahkan dalam peserta didik.

Pengelola pondok pesantren hendaknya mencari alternatif untuk lebih meningkatkan kegiatan pengembangan bahasa Arab, karena sangat penting dikuasai oleh peserta didik agar mampu berdaya saing, baik dalam level regional, nasional, maupun global.

\section{DAFTAR RUJUKAN}

Areepattamannil, S. Freeman, J.F. 2008. “Academic Achievement, Academic Self-Concept and Academic Motivation of Immigration Adolescent in the Greater Toronto Area Secondary School. Journal of Advanced Academic, Volume, 19, Nomor 14, h. 700-743.

Boediono. 2013. "Pendidikan Kunci Pembangunan”. Menyambut Kurikulum 2013, Editor; A. Ferry T. Inratno. Jakarta: Kompas Media Nusantara.

Chodidjah, I. 2013. "Jika Guru Gagal Dilatih, Gagal juga Perubahan Kurikulum 2013”. 
Menyambut Kurikulum 2013, Editor: A. Ferry T. Inratno. Jakarta: Kompas Media Nusantara.

Fausett, L. 1984. Fundamentals of Neural Network. New York: Prentice Hall.

Höffler, T.M, Bonin, V. Parchmann, I. 2017. "Science vs Sports: Motivation and SelfConcepts of Participants in Different School Competitions". International Journal of Science and Mathematic, 836, h. 818-836.

Höffler, T.M., Bonin, V. Parchmann, I. 2017. "Science vs Sports: Motivation and SelfConcepts of Participants in Different School Competitions". International Journal of Science and Mathematic, 836, h. 818-836.

Lim, S., Oliver, M. 2017. A Guide to International Biology Olympiad, Edition 12.0. http://www.ibo-info.org/pdf/IBO/-Guid.pdf diunduh pada 20 Januari 2017
Marh, H.W. 2004. "Negative Effect of School Average on Academic-Self -Concept Model: a Comparison of the Bigfish-Little Pond Effect across Australian States and Territories". Australian Education Research Journal, 48, h. 5-28.

Matovu, M. 2012. "Academic Self-Concept and Academic Achievement among University Students". International Online Journal of Educational Sciences, Vol. 4, Nomor 1, h. 107-116.

Spinath, B. Stainmayr, R. 2012. "The Role of Competence Beliefs and Goal Orientation for Chance in Intrinsic Motivation". Journal of Educational Psychology, 104 (4), h. 1135-1148.

Villegas, G., O. Tomasini, G., A. Lagunes, L.I.R. 2013. "Development of an Academic for Adolescent (ASCA)". Journal of Behavior, Health and Social Science, Volume 5, Nomor 2, h. 117-130. 
Education and Human Development Journal, Vol. 3, No. 2, September 2018 